\title{
Carbon-Doped Titanium Dioxide: Visible Light Photocatalysis and EPR Investigation
}

\author{
Elizaveta A. Konstantinova ${ }^{\mathrm{a}}$, Alexander I. Kokorin ${ }^{\star b}$, Shanmugasundaram Sakthivel ${ }^{\mathrm{c}}$, \\ Horst Kisch , and Klaus Lips ${ }^{\mathrm{d}}$
}

\begin{abstract}
X-band EPR studies of a series of undoped and carbon-doped titania powders reveal the presence of a carbon-centered radical species. The concentration of spins is five to six orders of magnitude smaller than the total carbon content. Photoexcitation of the carbon-doped samples increases the corresponding EPR signal intensities both under ultraviolet and visible light irradiation. After illumination, the original intensity is restored within a few hours. Samples with higher carbon radical concentration reveal higher photocatalytic activity in degradation of 4-chlorophenol under visible light irradiation.
\end{abstract}

Keywords: Carbon-doped titania · Doped semiconductors · EPR · Photocatalytic activity

\section{Introduction}

Titanium dioxide is known as the most important semiconductor photocatalyst because of its non-toxicity and high catalytic activity in various photooxidation reactions. However, its large band gap (approximately $3.2 \mathrm{eV}$ ) requires the use of $\mathrm{UV}$ light and, therefore, does not allow also the much larger visible part of solar light to be utilized. ${ }^{[1]}$ For this reason, during the last years many attempts were made to obtain a modified titania which would be photocatalytically active also with visible light. Typical examples are surface modification with metal complexes, ${ }^{[1 \mathrm{~g}]}$ doping with

${ }^{\star}$ Correspondence: Prof. A. I. Kokorin ${ }^{b}$

E-Mail: alex-kokorin@yandex.ru

aM. Lomonosov Moscow State University

Department of Physics

Leninskie Gory, 119992 Moscow, Russia

${ }^{b} \mathrm{~N}$. Semenov Institute of Chemical Physics RAS

Kosygin st. 4, 119991 Moscow, Russia

${ }^{`}$ Institut für Anorganische Chemie der Universität

Erlangen-Nürnberg

Egerlandstr.1, D-91058 Erlangen, Germany

dHahn-Meitner-Institut Berlin GmbH

Abt. Silizium-Photovoltaik

Kekuléstr. 5, Berlin, Germany transition metal ions ${ }^{[2,3]}$ and nonmetallic elements such as carbon, ${ }^{[4]}$ nitrogen, ${ }^{[5]}$ and sulfur. ${ }^{[6]}$ All these novel materials photocatalyze under visible light illumination complete mineralization of various pollutants in water and air, and some nitrogenor carbon-doped titania powders are active even in diffuse indoor daylight of very weak light intensity. ${ }^{[4,5 f]}$ Experimental and theoretical results indicated that these dopants generate localized energy levels (or surface states) just above the valence band from which visible light excitation becomes feasible. ${ }^{[4 c, 5 b, 5 k]}$ Due to these intra-bandgap states, the carbon-doped titania exhibits a weak sub-bandgap light absorption starting already at about $735 \mathrm{~nm} .{ }^{[4 \mathrm{c}]}$ These materials contained $0.4-4.0 \%$ carbon in the form of carbonate and elemental carbon as indicated by X-ray photoelectron spectra (XPS). ${ }^{[4]}$ It is noted that visible light activity in degradation reactions is not related to the presence of carbonate. ${ }^{[5 f]}$ To characterize these $\mathrm{C}$-doped materials in more detail, and to obtain basic information on the nature of the carbon dopants, we investigated the electronic properties by electron paramagnetic resonance (EPR) spectroscopy. This very sensitive method allows detection and characterization of paramagnetic defects, which may be of significant importance for the photocatalytic properties. ${ }^{[7]}$ For example, Y. Li et al. ascribed the visible light activity of C-doped $\mathrm{TiO}_{2}$ to the presence of oxygen vacancies as suggested by the EPR detection of $\mathrm{Ti}^{3+}$ species. ${ }^{[8]}$ However, it was noticed that the calculation of $g$-values was incorrectly performed and details on the wavelength of exciting light were missing.
In the following, we report on the photocatalytic activity and EPR spectra for a series of undoped and C-doped titania powders with the goal to clarify the nature of the paramagnetic centers and their changes upon illumination under well-defined conditions.

\section{Results and Discussion}

The titania materials investigated in this work were self-prepared $\left(\mathrm{TiO}_{2}-1\right)$, commercial $\left(\mathrm{TiO}_{2}-2\right.$ and $\left.\mathrm{TiO}_{2}-3\right)$; selfprepared volume-doped $\left(\mathrm{TiO}_{2}-\mathrm{Cla}\right.$ and $\left.\mathrm{TiO}_{2}-\mathrm{C} 1 \mathrm{~b}\right)$, self-prepared surface-doped samples $\left(\mathrm{TiO}_{2}-\mathrm{C} 2\right)$ and commercial $\left(\mathrm{TiO}_{2}-\mathrm{C} 3\right)$. According to XPS and IR data (not shown here), the volume-doped $\mathrm{TiO}_{2}-\mathrm{Cla}$, contains in addition to elemental carbon species $(\mathrm{C} 1 \mathrm{~s}$ binding energy of $284.5 \mathrm{eV}$ ), also a carbonate signal at 289.4 $\mathrm{eV}$, whereas the latter is absent in the surface-doped sample $\mathrm{TiO}_{2}-\mathrm{C} 2$ containing a shifted C1s signal at $285.8 \mathrm{eV}$ (Fig. 1).

\section{Photocatalytic Activity}

The visible light activity $(\lambda \geq 455 \mathrm{~nm})$ of various photocatalysts is summarized in Fig. 2 for the mineralization of 4-chloropheneol, a common pollutant in water. Whereas unmodified titania is inactive under these irradiation conditions, all carbondoped samples are highly active. Out of these, the bulk modified material $\mathrm{TiO}_{2}-\mathrm{Cla}$ is the most active one, although the difference from the surface modified sample $\mathrm{TiO}_{2}-\mathrm{C} 2$ is less than from the other bulk modified powder $\mathrm{TiO}_{2}-\mathrm{C} 1 \mathrm{~b}$. 

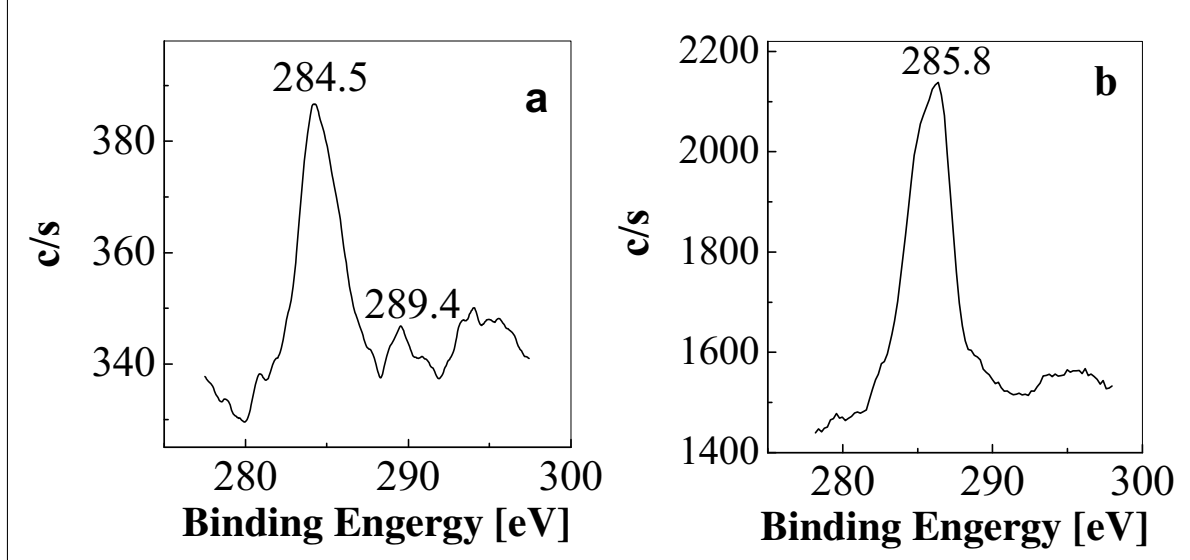

Fig. 1. C1s binding energies of a) $\mathrm{TiO}_{2}-\mathrm{C} 1 \mathrm{a}$ and b) $\mathrm{TiO}_{2}-\mathrm{C} 2$.
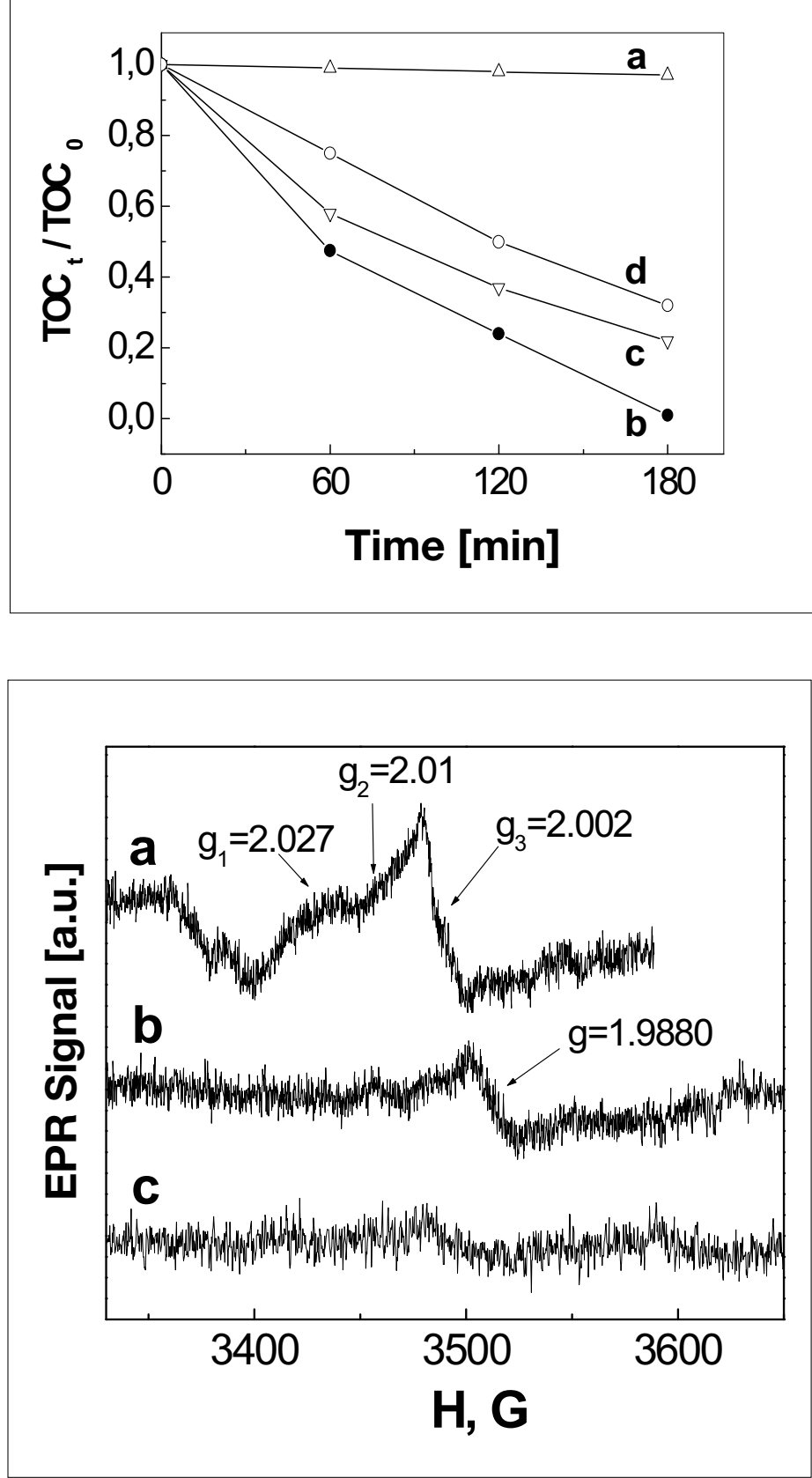

Fig. 3. EPR spectra of undoped samples at $300 \mathrm{~K}$ : a) $\mathrm{TiO}_{2}-1$, b) $\mathrm{TiO}_{2}-2$, c) $\mathrm{TiO}_{2}-3$. Arrows indicate the position of $g$-values.

\section{EPR Spectra in the Absence of Irradiation}

All samples exhibited EPR signals that did not change over several months when the powders were kept in the dark at room temperature. Typical EPR spectra of three undoped samples: $\mathrm{TiO}_{2}-1, \mathrm{TiO}_{2}-2$ and $\mathrm{TiO}_{2}-3$ at $300 \mathrm{~K}$ are shown in Fig. 3 .

All signals reveal very low intensities; the $\mathrm{g}$-factor values of paramagnetic centers in $\mathrm{TiO}_{2}$ particles are equal to: $\mathrm{g}_{1}=2.0270 \pm$ $0.0005, \mathrm{~g}_{2}=2.0100 \pm 0.0005, \mathrm{~g}_{3}=2.0020$ \pm 0.0005 (Fig. 3, curve a). These parameters coincide well with those from literature. ${ }^{[9,10]}$ Paramagnetic centers of such type can be ascribed to $\mathrm{O}_{2}{ }^{-}$radicals on the $\mathrm{TiO}_{2}$ particle surface. The signal with $g=1.9880$ \pm 0.0005 (Fig. 3, curve b) may be attributed to $\mathrm{Ti}^{3+}$ centers (oxygen vacancies), which are usually detected only at temperatures below $120 \mathrm{~K} \cdot{ }^{[11]}$ The last EPR signal (curve c) is at the noise level and will not be discussed. The detected concentration measured at $5 \mathrm{~K}$ in the undoped samples is very low, approximately $\mathrm{N}_{1} \approx 8 \cdot 10^{14} \mathrm{spin} / \mathrm{g}$ for $\left(\mathrm{TiO}_{2}-1\right)$ and $\mathrm{N}_{2} \approx 10^{14} \mathrm{spin} / \mathrm{g}$ for $\left(\mathrm{TiO}_{2}-2\right)$, respectively.

EPR signals of surface-doped $\mathrm{TiO}_{2}$
Fig. 2.

Photomineralization of 4-chlorophenol (C $=2.5 \times 10^{-4} \mathrm{~mol} \cdot \mathrm{I}^{-1}$, $\mathrm{TOC}_{0}$ and $\mathrm{TOC}_{\mathrm{t}}$ are Total Organic Carbon content at times equal to 0 and $t), \lambda$ $\geq 455 \mathrm{~nm}$; (a) $\mathrm{TiO}_{2}-2$, (b) $\mathrm{TiO}_{2}-\mathrm{C} 1 \mathrm{a},(\mathrm{c})$ $\mathrm{TiO}_{2}-\mathrm{C} 2$, (d) $\mathrm{TiO}_{2}-$ C1b. samples $\mathrm{TiO}_{2}-\mathrm{C} 2$ and $\mathrm{TiO}_{2}-\mathrm{C} 3$ at $5 \mathrm{~K}$ and $300 \mathrm{~K}$ are practically isotropic and of rather high intensity. Their g-values of $2.0030 \pm$ 0.0005 are identical whereas the line widths of $4.7 \pm 0.2 \mathrm{G}$ and of $3.7 \pm 0.2 \mathrm{G}$ are a little different for $\mathrm{TiO}_{2}-\mathrm{C} 2$ and $\mathrm{TiO}_{2}-\mathrm{C} 3$, respectively (Fig. 4).

The measured concentrations are equal to $2 \times 10^{16}\left(\mathrm{TiO}_{2}-\mathrm{C} 2\right)$ and $4 \times 10^{15} \mathrm{spin} / \mathrm{g}$ $\left(\mathrm{TiO}_{2}-\mathrm{C} 3\right)$. From the facts that the EPR signal arises after $\mathrm{C}$ doping, that the g-value is

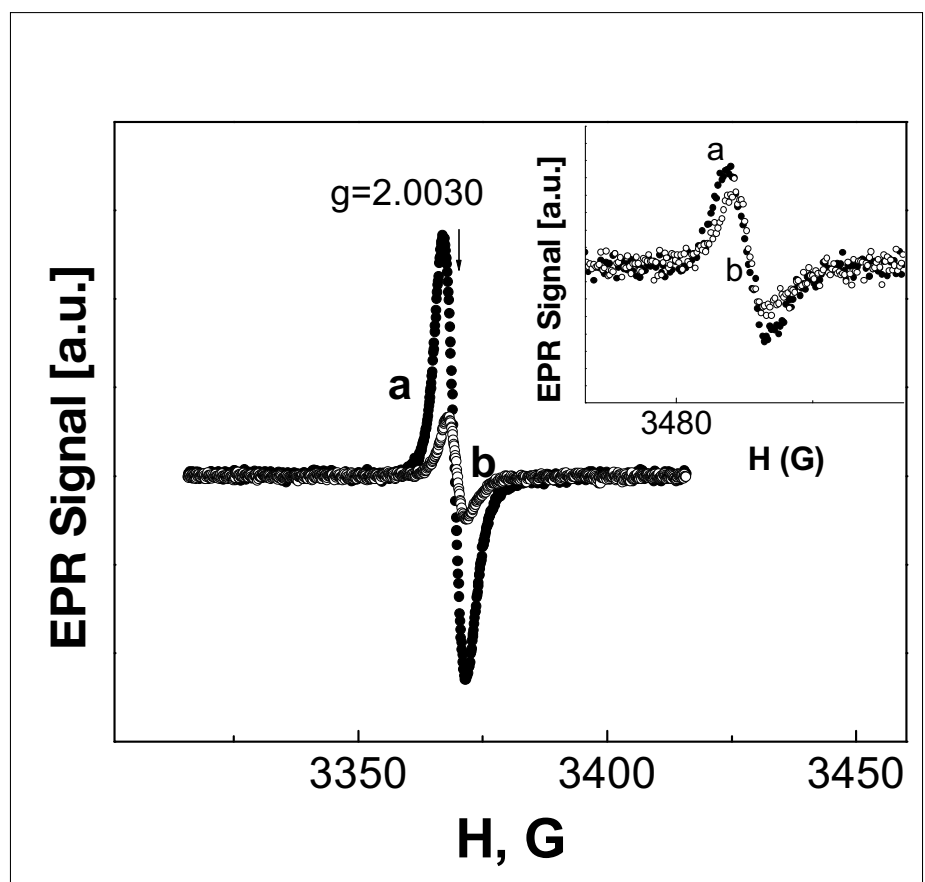

Fig. 4. EPR spectra of surface-doped samples at $5 \mathrm{~K}$ : a) $\mathrm{TiO}_{2}-\mathrm{C} 2$, b) $\mathrm{TiO}_{2}-\mathrm{C} 3$. Inset shows the same samples but at $300 \mathrm{~K}$. Arrows indicate the position of g-value. 
typical for carbon radicals, and that samples with higher carbon content in general have a higher content of paramagnetic centers, one can conclude that the signals belong to the carbon dopant. Similar EPR data were reported for the carbon dangling bonds (DB) in amorphous carbon particles. ${ }^{[12 a, b]}$ The assumption that this signal belongs to conduction band electrons trapped at oxygen vacancies ${ }^{[8,13]}$ seems to be not valid because the signal is related to the carbon content, and to very low concentration of $\mathrm{Ti}^{3+} /$ oxygen vacancy centers, although it cannot be neglected completely.

It was noticed that the shape of EPR spectrum and the main parameters were constant for both samples at $300 \mathrm{~K}, 77 \mathrm{~K}$, and $5 \mathrm{~K}$ (Fig. 4, inset). This fact reflects the negligible role of spin-lattice relaxation in these samples. Since EPR spectra and their parameters for all investigated samples did not change in the temperature range from 77 to $5 \mathrm{~K}$, measurements were usually performed at $77 \mathrm{~K}$ because of experimental simplicity.

The volume-doped sample $\mathrm{TiO}_{2}-\mathrm{Cla}$ exhibits at $5 \mathrm{~K}$ a completely different EPR spectrum (Fig. 5a). As concluded from the asymmetric shape of the main signal with the g-factor values of $\mathrm{g}_{1}=$ $2.0043 \pm 0.0005, \mathrm{~g}_{2}=2.0027 \pm 0.0005$, $\mathrm{g}_{3}=1.9801 \pm 0.0005$ (the computer simulation is reported in Fig. 5b), it can be assigned to a $\mathrm{CO}_{2}{ }^{-}$radical, when compared with measurements in $\mathrm{MgO}, \mathrm{NaHCO}_{3}$ and $\mathrm{KHCO}_{3} \cdot{ }^{[14-16]}$ The relatively higher intensity of the peak at $\mathrm{g}=2.0027$, as compared to the literature spectrum, ${ }^{[14-16]}$ shows that paramagnetic carbon species are also pres- ent in this volume-doped sample in addition to the $\mathrm{CO}_{2}^{-}$radical, as in the surfacedoped material.

The EPR signal is detectable at room temperature, but with lower signal-tonoise ratio (Fig. 5, inset). Also, at the same magnetic field, a spectrum of $\mathrm{O}^{-}$-radicals is usually observed in $\mathrm{TiO}_{2}$ materials. The $\mathrm{g}$-values of $\mathrm{O}^{-}$-radicals in various matrixes are: $\mathrm{g}_{1}=2.020-2.028, \mathrm{~g}_{2}=2.009-2.019$, and $\mathrm{g}_{3}=2.002-2.0073 \cdot[11,17,18]$ Therefore, because of superposition of EPR lines of several paramagnetic centers, we cannot do the complete interpretation of the whole experimental spectrum. Taking into account the EPR signal around $g=1.9801-2.034$ (Fig. 5) and the absence of a $\mathrm{Ti}^{3+}$ signal for this sample, one can assume that $\mathrm{CO}_{2}^{-}$is formed during the calcination step as proposed by Eqns (1) and (2):

$\mathrm{CO}_{2}+\mathrm{O}^{2-}$ (lattice) $=\mathrm{CO}_{2}^{-}+\mathrm{O}^{-}$(lattice)

$\mathrm{CO}_{2}+\mathrm{Ti}^{3+}$ (lattice) $=\mathrm{CO}_{2}^{-}+\mathrm{Ti}^{4+}$ (lattice)

The concentration of paramagnetic defects in $\mathrm{TiO}_{2}-\mathrm{Cl}$ a samples is estimated as $\approx 10^{15} \mathrm{spin} / \mathrm{g}$.

\section{EPR Spectra under Irradiation}

Under visible light illumination, no changes in EPR spectra of the undoped $\mathrm{TiO}_{2}$ samples were detected. Contrary to this, visible light illumination of all doped $\mathrm{TiO}_{2}$ samples results in a growth of the EPR signals. As an example, the effect of light illumination is shown in Fig. 6 for surfacedoped $\mathrm{TiO}_{2}-\mathrm{C} 2$ at $5 \mathrm{~K}$.

The signal intensity noticeably increases during illumination (Fig. 6, curve b) and slowly decreases towards its original level after turning off the light (Fig. 6, curve c). After $10 \mathrm{~min}$ the remaining intensity was about $25 \%$ compared to the illuminated sample. Complete recovery of the EPR signal was not observed at this temperature. This behavior can be explained by assuming that photoexcitation promotes an electron from the major and diamagnetic carbon dopant species $\mathrm{C}_{\mathrm{x}}$ to the conduction band leading to a carbon-centered radical and a trapped electron. At room temperature, complete charge recombination results in recovery of the initial intensity after $\sim 30 \mathrm{~min}$.

In addition to line intensity, also the line width increases upon illumination at 5 $\mathrm{K}$ from $3.7 \mathrm{G}$ to $4.7 \mathrm{G}$ (Fig. 6). However, this value did not change upon warming up to ambient temperature. Such behavior is typical for EPR lines with inhomogeneous broadening. ${ }^{[19]}$

To further clarify whether these paramagnetic centers are involved in photocatalytic reactions, surface-doped $\mathrm{TiO}_{2}-\mathrm{C} 2$ and volume-doped $\mathrm{TiO}_{2}-1 \mathrm{~b}$ samples were illuminated at $77 \mathrm{~K}$ at 578 and $365 \mathrm{~nm}$. After illuminating $\mathrm{TiO}_{2}-\mathrm{C} 2$ for $28 \mathrm{~min}$ at $578 \mathrm{~nm}$ (Fig. 7, curve a), light was turned off and the signal decay was monitored at $77 \mathrm{~K}$ for 11 min (Fig. 7, curve c). Upon subsequent standing at ambient temperature, the signal amplitude recovered back to its initial level. Thereafter, the sample was cooled to $77 \mathrm{~K}$ and illuminated at $365 \mathrm{~nm}$ (Fig. 7, curve b). After $5 \mathrm{~h}$ and $10 \mathrm{~h}$ of continuous illu-

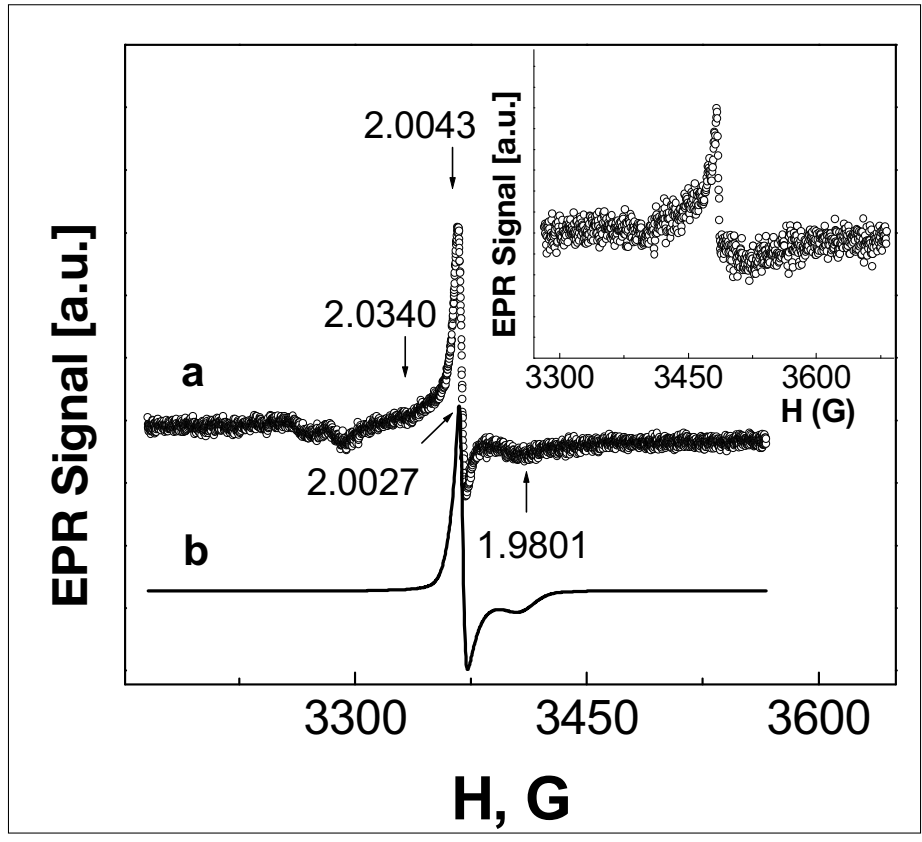

Fig. 5. Experimental EPR spectrum of volume-doped $\mathrm{TiO}_{2}-\mathrm{C} 1 \mathrm{a}$ at $5 \mathrm{~K}$ (a) and simulated spectrum of $\mathrm{CO}_{2}{ }^{-}$species (b). Inset shows the same sample at $300 \mathrm{~K}$. Arrows indicate the position of $g$-values.

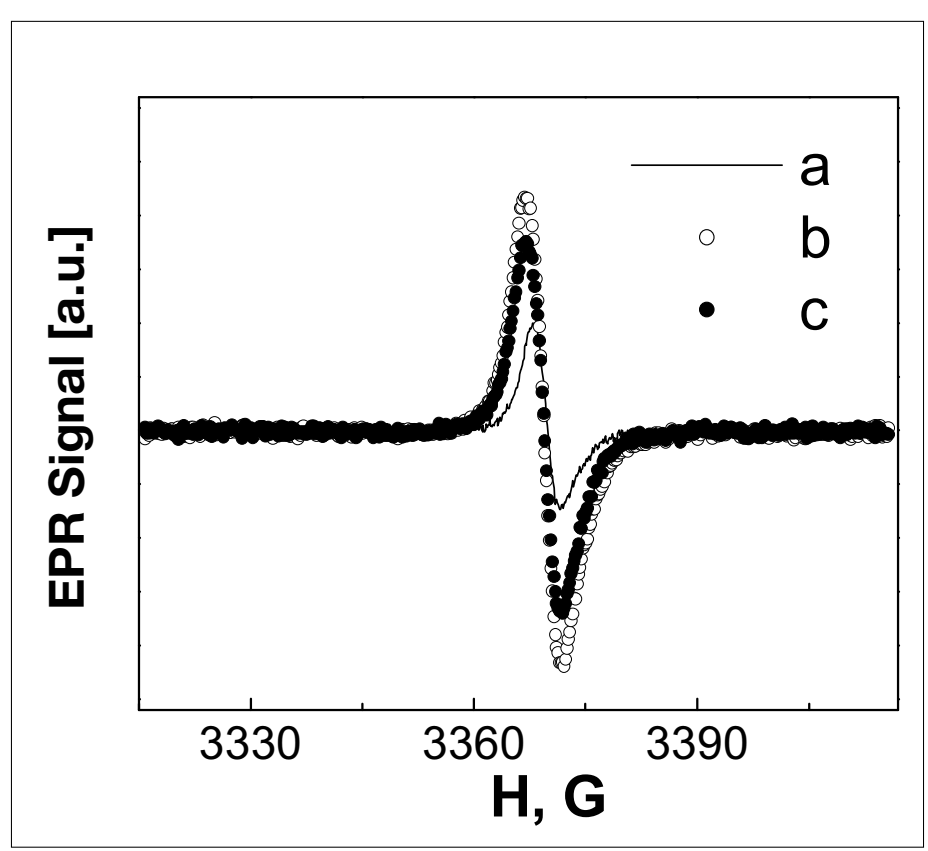

Fig. 6. EPR spectra of surface-doped $\mathrm{TiO}_{2}-\mathrm{C} 2$ sample at $5 \mathrm{~K}$ : a) before visible light illumination, b) under illumination, c) 15 min after illumination; $\lambda \geq 400 \mathrm{~nm}$. 


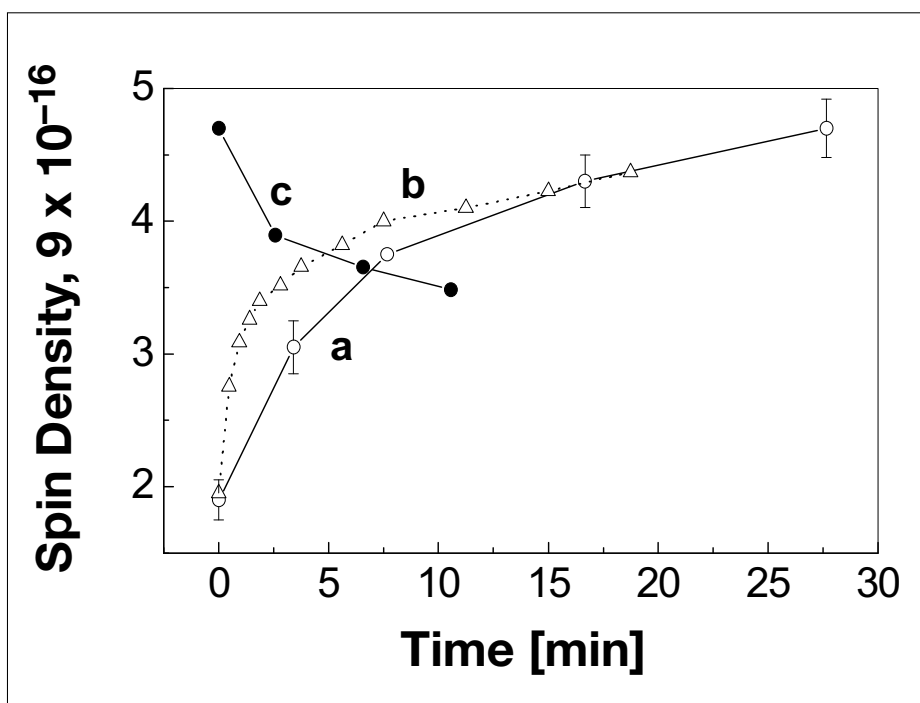

Fig. 7. Kinetic curves of the defects content under illumination at $\lambda=578$ $\mathrm{nm}$ (curve a), $365 \mathrm{~nm}$ (curve b) and the signal decay in the dark (curve c) for surface-doped $\mathrm{TiO}_{2}-\mathrm{C} 2$ at $77 \mathrm{~K}$.

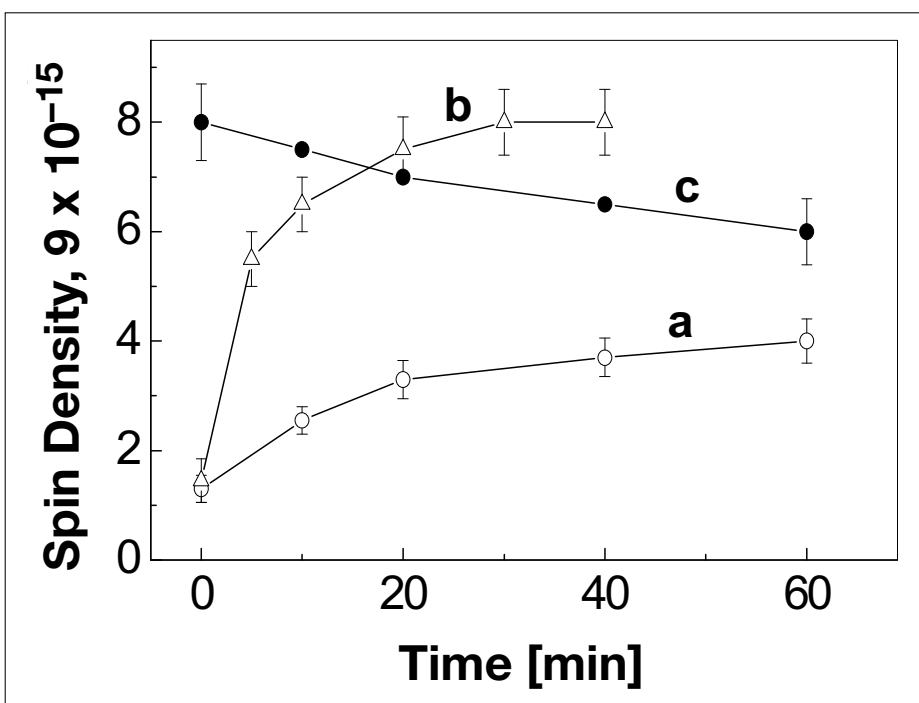

Fig. 8. Kinetic curves of the defect content under illumination with $\lambda=578$ $\mathrm{nm}$ (curve a), $365 \mathrm{~nm}$ (curve b) and the signal decay in the dark (curve c) for volume-doped $\mathrm{TiO}_{2}-\mathrm{C} 1 \mathrm{~b}$ at $77 \mathrm{~K}$. mination, the concentration of defects was equal to $5.2 \times 10^{16}$ and $5.0 \times 10^{16} \mathrm{spin} / \mathrm{g}$, respectively.

This difference is within the limit of accuracy of our measurements. Comparing this concentration with the one obtained just after 15-20 min of illumination one can conclude that the equilibrium between defect generation and defect decay was practically reached after the first $20-30 \mathrm{~min}$ of illumination.

Analogous experiments have been performed with $\mathrm{a} \mathrm{TiO}_{2}-\mathrm{C} 1 \mathrm{~b}$ sample containing much smaller amounts of doping carbon species (Fig. 8). In this case, the defect content increased approximately twofold and fourfold upon $40 \mathrm{~min}$ irradiating at $578 \mathrm{~nm}$ (Fig.8, curve a) or $365 \mathrm{~nm}$ (Fig. 8, curve b), respectively.

The decay of the EPR signal in the dark at $77 \mathrm{~K}$ (Fig. 8, curve c) was noticeably slower in comparison with that of surfacedoped $\mathrm{C}_{-}-\mathrm{TiO}_{2}-2(\sim 20 \%$ after one hour $v s$. $26 \%$ after $\sim 11 \mathrm{~min}$ ) as evidenced by the results depicted in Figs. 7 and 8. Notice that the EPR signal in $\mathrm{TiO}_{2}-\mathrm{C} 1 \mathrm{~b}$ samples is due to the superposition of $\mathrm{CO}_{2}^{-}$-radicals and carbon dangling bonds.

\section{Conclusion}

The comparison of undoped with Cdoped samples clearly reveals that the EPR signals of both volume- and surface-doped titania originate from radical carbon species $\mathrm{CO}_{2}{ }^{-} / \mathrm{C}_{\mathrm{x}}$ and $\mathrm{C}_{\mathrm{x}}$, respectively (see Figs. 4 and 5). Accordingly, the concentration of spins in surface-doped materials $\mathrm{TiO}_{2}-\mathrm{C} 2$ and $\mathrm{TiO}_{2}-\mathrm{C} 3$ decreases from $2 \times$ $10^{16} \mathrm{spin} / \mathrm{g}$ to $4 \times 10^{15} \mathrm{spin} / \mathrm{g}$ in agreement with the carbon content of 1.05 and 0.46 $\mathrm{wt} \%$, respectively. It is noted that these spin densities are about five to six orders of magnitude lower than the total content of carbon atoms, which is $c a \cdot 7 \cdot 10^{21}$ and $7 \cdot 10^{20}$ atom/g, respectively. The observation that irradiation both in the UV or Vis region increases the concentration of these carboncentered radicals may suggest that they are involved in the photocatalytic degradation reaction. However, their long life-time of about half an hour at room temperature disfavors this assumption, although it cannot be completely ruled out.

\section{Experimental Section}

The undoped material $\mathrm{TiO}_{2}-1$ was self prepared through hydrolysis of titanium tetrachloride $\left(\mathrm{TiCl}_{4}\right)^{[4 \mathrm{c}]}$ whereas $\mathrm{TiO}_{2}-2$ and $\mathrm{TiO}_{2}-3$ were commercial products from KerrMcGee Pigments GmbH (Titanhydrat) and Kronos International Inc., respectively. Bulk modified materials $\mathrm{TiO}_{2}-\mathrm{Cla}$ and $\mathrm{TiO}_{2}-\mathrm{C} 1 \mathrm{~b}$ containing 2.48 and 0.42 wt $\%$ carbon respectively were prepared through hydrolysis of $\mathrm{TiCl}_{4}$ with tetrabutylammonium hydroxide followed by calcination at $400{ }^{\circ} \mathrm{C}$ for $1 \mathrm{~h}$, and at $350{ }^{\circ} \mathrm{C}$ for $2 \mathrm{~h}$, respectively. ${ }_{[4 \mathrm{c}]}$ The surface modified sample $\mathrm{TiO}_{2}-\mathrm{C} 2$ containing $1.05 \mathrm{wt} \%$ carbon, was prepared by suspending $3 \mathrm{~g}$ of titanium dioxide (Kerr-McGee Pigments $\mathrm{GmbH}$ ) and $4 \mathrm{ml}$ of glycerol in $50 \mathrm{ml}$ of distilled water. After sonicating for $30 \mathrm{~min}$, the suspension was stirred magnetically overnight, and the solvent was removed. Thereafter, the residue was crushed to a fine powder and calcined in air for $30 \mathrm{~min}$ at $300^{\circ} \mathrm{C}$. The sample $\mathrm{TiO}_{2}-\mathrm{C} 3$ was a commercially available surface-modified material and contained 0.46 wt\% of carbon (Kronos International Inc.).
All wt\% values of carbon reported in this paper were obtained by elemental analysis. According to X-ray diffraction, all samples are of the anatase modification.

Photodegradation of 4-chlorophenol was carried out in a jacketed cylindrical $15 \mathrm{ml}$ quartz cuvette attached to an optical train. Irradiation was performed with an Osram XBO $150 \mathrm{~W}$ xenon arc lamp installed in a light-condensing lamp housing (PTI, A1010S). A water filter and a 455 $\mathrm{nm}$ cut-off filter were placed in front of the cuvette. Running water was circulated through the jacket to ensure constant temperature of the reaction mixture, which was stirred magnetically. TOC measurements were made on a Shimadzu Total Carbon Analyzer TOC-500/5050 with NDIR optical system detector.

EPR spectra were detected by a standard Bruker EPR spectrometer Elexsys-580 (Xband, sensitivity is around $\sim 10^{10} \mathrm{spin} / \mathrm{G}$, modulation frequency $100 \mathrm{kHz}$ ). $\mathrm{Mn}^{2+}$ in $\mathrm{MgO}$ was employed as reference for g-values. After filling the powder into a quartz tube, it was evacuated to $7 \times 10^{-6} \mathrm{mBar}$ for 30 minutes followed by filling with $\mathrm{He}$ gas up to a pressure of $10^{-1}-10^{-2}$ Torr, and sealing of the tubes. The samples were investigated at 300,77 , and $5 \mathrm{~K}$.

Samples were illuminated (in situ) at 77 and $5 \mathrm{~K}$ with a $100 \mathrm{~W}$ tungsten halogen lamp in the spectral range of $\lambda \geq 400 \mathrm{~nm}$ and with a $250 \mathrm{~W}$ high-pressure mercury lamp in the case of monochromatic irradiation at 578 and $365 \mathrm{~nm}$ through inserting appropriate cut-off and interference filters, respectively.

\section{Acknowledgements}

E.A.K. is indebted to Hahn-MeitnerInstitute, Berlin, for financial support. Helpful 
discussions with Dr. V. I. Pergushov and Prof. M. Ya. Mel'nikov (M. Lomonosov Moscow State University, Chemical Department) are gratefully acknowledged. The preparative and photocatalytic part of this work $(\mathrm{H}$. K. and S. S.) was supported by Deutsche Forschungsgemeinschaft (SFB 583)

\section{Received: October 21, 2007}

[1] a) M. Schiavello, 'Photoelectrochemistry, Photocatalysis and Photoreactors', Reidel Publ. Co., Dordrecht, 1985; b) N. Serpone, E. Pelizzetti, 'Photocatalysis: Fundamentals and Applications', Wiley \& Sons, New York, 1989; c) D. F. Ollis, H. Al-Ekabi, 'Photocatalytic Purification and Treatment of Water and Air', Elsevier, Amsterdam, 1993; d) M. R. Hoffmann, S. T. Martin, W. Choi, D. W. Bahnemann, Chem. Rev. 1995, 95, 69; e) E. Pelizzetti, N. Serpone, 'Homogeneous and Heterogeneous Photocatalysis', Reidel Publ. Co., Dordrecht, 1986; f) A. Mills, S. Le Hunte, J. Photochem. Photobiol. A: Chem. 1997, 108, 1; g) H. Kisch, G. Burgeth, W. Macyk, Adv. Inorg. Chem. 2004, 56, 241.

[2] a) H. Yamashita, M. Honda, M. Harada, Y. Ichihashi, M. Anpo, T. Hirao, N. Itoh, N. Iwamoto, J. Phys. Chem. B 1998, 102, 10707; b) M. Anpo, M. Takeuchi, Int. J. Photoenergy $20013,1$.

[3] a) D. W. Bahnemann, S. N. Kholuiskaya, R. Dillert, A. I. Kulak, A. I. Kokorin, Appl. Catalysis, B: Environ. 2002, 36, 161; b) D. G. Shchukin, A. I. Kulak, D. V. Sviridov, Photochem. Photobiol. Sci. 2002, 1, 742; c) H. Kisch, W. Macyk, Chem. Phys. Chem. 2002, 3, 399.

[4] a) C. Lettmann, K. Hildenbrand, H. Kisch, W. Macyk, W. F. Maier, Applied Catalysis B: Environ. 2001, 32, 215; b) S. U. M. Khan, M. Al-Shahry, W. B. Ingler Jr., Science 2002, 297, 2243; c) S. Sakthivel, H. Kisch, Angew. Chem. 2003, 115, 5057; Angew. Chem., Int. Ed. 2003, 42, 4908.

[5] a) S. Sato, Chem. Phys. Lett. 1986, 123, 126; b) R. Asahi, T. Morikawa, T. Ohwaki, A. Aoki, Y. Taga, Science 2001, 293, 269; c) S. Sakthivel, H. Kisch, ChemPhysChem 2003, 4, 487; d) T. Lindgren, J. M. Mwabora, E. Avendano, J. Jansson, A Hoel, C.-G. Granqvist, S.-E. Lindquist, J. Phys. Chem. B 2003, 107, 5709; e) H. Irie, Y. Watanabe, K. Hashimoto, J. Phys. Chem. B 2003, 107, 5483; f) S. Sakthivel, M. Janczarek, H. Kisch, J. Phys. Chem. B 2004, 108, 19384; g) J. L. Gole, J. D. Stout, C. Burda, Y. Lou, X. Chen, J. Phys.
Chem. B 2004, 108, 1230; h) O. Diwald, T. L. Thomson, T. Zubkov, E. G. Goralski, S. D. Walck, J. T. Yates, J. Phys. Chem. B 2004, 108, 6004; i) D. Li, H. Haneda, S. Hishita, N. Ohashi, Mater. Sci. Eng. $B$ 2005, 117, 67; j) S. Livraghi, A. Votta, M. C. Paganini, E. Giamello, Chem. Commun. 2005, 4, 498; k) C. Di Valentin, G. Pacchioni, A. Selloni, Chem. Mater. 2005, 17, 6656.

[6] T. Umebayashi, T. Yamaki, S. Tanaka, K. Asai, Chem. Lett. 2003, 32, 330.

[7] a) T. Rajh, O. G. Poluektov, M. C. Thurnauer, in 'Chemical Physics of Nanostructured Semiconductors', Eds. A. I. Kokorin, D. W. Bahnemann, VSPBrill Academic Publishers, Utrecht, Boston, 2003; b) A. I. Kokorin, in 'Chemical Physics of Nanostructured Semiconductors', Eds. A. I. Kokorin, D. W. Bahnemann, VSP-Brill Academic Publishers, Utrecht, Boston, 2003, 203.

[8] Y. Li, D.-S. Hwang, N. H. Lee, S.-J. Kim, Chem. Phys. Lett. 2005, 404, 25.

[9] R. F. Howe, M. J. Grätzel, J. Phys. Chem 1987, 91, 3906.

[10] P. C. Gravelle, F. Juilett, P. Meriaudeau, S. J. Teichner, Faraday Discus. Chem. Soc. 1971, 140 .

[11] a) O. I. Micic, Y. Zhang, K. R. Cromack, A. D. Trifunac, M. C. Thurnauer, J. Phys. Chem. 1993, 97, 7277; b) M. Anpo, M. Yabuta, S. Kodama, Y. Kubokawa, Bull. Chem. Soc. Japan 1986, 59, 259.

[12] a) I. Watanabe, T. Okumura, Jpn. J. of Appl. Phys. 1985, 24, L122; b) D. J. Miller, D. R. Mckenzie, Thin Solid Films 1983, 108, 257; c) 'Amorphous Semiconductors. Technology \& Devices', Ed.Y.Hamakawa, OHM \& North-Holland, Tokyo-Amsterdam-Oxford, 1983, 85.

[13] E. Serwicka, M. W. Schlierkamp, R. N Schindler, Z. Naturforsch. 1981, 36a, 226.

[14] J. H. Linsford, J. P. Jayne, J. Phys. Chem. 1965, 69, 2182

[15] D. W. Ovenall, D. H. Whiffen, Mol. Phys. 1961, 4, 135.

[16] P. W. Atkins, N. Keen, M. C. R. Symons, J. Chem. Soc. 1962, 2873.

[17] Y. Nakaoka, Y. Nasaka, J. Photochem. Photobiol. A 1997, 110, 299.

[18] I. D. Mikhiekin, A. I. Maschenko, V. B. Kazanskii, Kinetika I Kataliz 1967, 8, 1363.

[19] a) A. Abragam, 'The principles of nuclear magnetism', Clarendon Press, Oxford, 1961; b) Y. S. Lebedev, V. I. Muromtsev, 'EPR and relaxation of the stabilized radicals', Khimiya, Moscow, 1971. 